\title{
Política e Poder no Paraguai
}

José Aparecido Rolon (*)

Resumo: Este trabalho propõe-se a discutir a política e o poder no Paraguai. A intenção aqui é, numa perspectiva histórica, apresentar sua cultura política, analisá-la e caracterizála no governo do general Alfredo Stroessner. Para definir esse período, foi utilizada a expressão espanhola stronismo, muito recorrente na literatura paraguaia. Em função disso serão apresentados quatro modelos de interpretação do regime stronista, conforme essa mesma literatura.

Palavras-chave: Paraguai, Política Interna, Stronismo, Poder, Cultura Política.

Abstract: This study aims at discussing politics and power in Paraguay. The focus is to show, from a historical perspective, the Paraguayan political culture; analyze it, and characterize it during General Alfredo Stroessner's government. To define this period, the Spanish expression stronismo (recurring in the Paraguayan literature) was used. Hence, four models of interpretation of the stronistic regime will be presented, following the above mentioned literature.

Keywords: Paraguay, Internal politics, Stronismo, Power, Political Culture.

(*) Doutor em Ciência Política pela Universidade de São Paulo. Professor da Universidade Anhembi Morumbi. Este artigo é resultado da tese de doutoramento apresentada pelo autor no Departamento de Ciência Política da FFLCH/USP, cujo título foi "Paraguai: transição democrática e política externa. E-mail: <rolon@ig.com.br>. Recebido em 21.4.2010 e aceito em 30.11.2010. 


\section{INTRODUÇÃo}

O Paraguai contemporâneo pode ser considerado como um país emblemático, posto que sua imagem frequentemente esteve associada aos aspectos mais negativos, tais como o de um país às voltas com o contrabando nas regiões de fronteira com a Argentina e o Brasil por um lado e de outro à sua instabilidade política. Essas problemáticas, dentre outras, parecem caracterizá-lo de forma indefinida.

Este artigo fugindo às essas tratativas e preconceitos, ao focar um aspecto - apesar de muito especulado, mas pouco conhecido - que é da sua cultura política, vai discuti-lo numa perspectiva histórica mais ampla com o fito de analisá-lo e encaminhar para sua caracterização mais específica no governo do general Alfredo Stroessner. A respeito desse período o do stronismo ${ }^{(1)}$, muito se tem falado e discutido. Desta forma, apresentaremos quatro modelos interpretativos que buscam uma definição mais precisa desse regime, o qual nem sempre pode ser corretamente interpretado à luz dos conceitos clássicos de dominação. Vale destacar ainda que a escolha desse período se dá em razão das transfor-mações estruturais, políticas e econômicas pelas quais o país passou e além disso com o ocaso do regime dá-se início à sua transição política.

Deste modo, o artigo divide-se basicamente em duas seções. Na primeira, será apresentada e discutida sua tradição política, cuja característica elementar para a saída ou chegada ao poder se dá pela violência. Na segunda, analisar-se-á a política e o poder no regime stronista, bem como apresentar-se-á os modelos interpretativos desse regime. E, finalmente, faremos as considerações finais, como fechamento do trabalho.

\section{Cultura política}

No Cone Sul, o Paraguai - sob vários aspectos e, sobretudo, do ponto de vista político - é seguramente o país de maior fragilidade institucional, com exígua experiência democrática, pois, ao longo de seu processo histórico, foi governado por uma elite cívico-militar com forte e rígido controle sobre a sociedade civil. Outra característica - por certo ambígua - é que até o governo de Alfredo Stroessner uns poucos governantes (dentre os inúmeros) destacaram-se por sua longevidade no poder ${ }^{(2)}$. E ainda houve um grande número de governos que exerceram o poder de maneira extremamente fugaz.

É o caso, por exemplo, das figuras dos chamados provisoriatos, que surgem aqui e ali na história política paraguaia, cuja função foi sempre a de exercer o poder interinamente diante desta ou daquela circunstância. Eles basicamente foram vice-presidentes que

(1) Para definir esse período, foi utilizada a expressão espanhola stronismo, muito recorrente na literatura paraguaia, conceito este que será discutido no decorrer do artigo.

(2) De acordo com Júlio César Frutos e Helio Vera (1998, p. 14), os governos de José Gaspar de Francia (1813-1840); Carlos A. Lopez (1840-1862); Francisco Solano Lopez (1862-1870); Higino Morínigo (1940-1948) e finalmente Alfredo Stroessner (1954-1989) são exemplos dessa longevidade. Juntos somam quase 110 anos no poder em um país com cerca de 187 anos de autonomia política. 
estiveram no poder em razão de falecimento, deposição ou renúncia dos titulares, ou ainda, mais raramente por designação do Congresso ${ }^{(3)}$.

Somente em 1998 ocorreram eleições em condições tidas como normais — fato considerado atípico e inédito em sua história política — porém, saiu vencedor o centenário Partido Colorado. A instabilidade e a violência política têm sido um dos traços da sociedade paraguaia. Segundo Frutos e Vera (1988, p. 13), no Paraguai, chegar ao poder e dele sair, no curso de sua história, significa utilizar-se de meios violentos. Há um apego ao poder, o que explica o fato de as transições não se darem de forma pacífica. Revolução ${ }^{(4)}$ - expressão de uso frequente na literatura política paraguaia para referir-se às mudanças - significa: cuartelazo, guerra civil ou golpe de Estado. Os conflitos são resolvidos pela truculência (FRUTOS; VERA, 1998, p. 21). Trata-se de uma história, em que a maioria foi sempre subjugada por uma minoria.

Tradicionalmente, o poder tem encontrado guarida em dois partidos centenários ${ }^{(5)}$, cuja base de sustentação se dá no caudilhismo tradicional, no funcionalismo público e no Exército. Este último, até a década de 1930, era um instrumento de líderes carismáticos, contudo, a partir desse período, passou a agir de forma corporativa com projeto político próprio.

A respeito dos partidos políticos no Paraguai, convém uma pequena digressão histórica para desfazer mal-entendidos e obter-se uma melhor compreensão da importância deles na sua história e na vida política.

Segundo Diego Abente (1996, p. 36), "el sistema de partidos paraguayo es uno de los menos estudiados y más malentendidos de América Latina...”. O desenvolvimento do sistema de partidos paraguaio está vinculado a dois períodos históricos diferentes. Um de 1870 até 1940 e outro dos anos de 1940 até a queda de Alfredo Stroessner, em 1989.

No primeiro período, encontram-se as origens dos partidos tradicionais (predominantes na maior parte de sua história) e, no segundo, ocorrem as transformações em suas estruturas, a correlação de forças e a modificação em sua relação com as Forças Armadas (ABENTE, 1996, p. 40). Nos primeiros tempos até os anos de 1940, verificase o predomínio de uma política oligárquica semicompetitiva, dominada por uma pequena elite de políticos e empresários. E, como já referido, a transferência de poder não se dá de forma pacífica.

Contudo, de acordo com Diego Abente, nesse período, o Paraguai, politicamente, encontra-se no mesmo patamar dos demais países latino-americanos, como Argentina, México e Uruguai, tanto no que se refere às mazelas - casos da existência de fraudes e

(3) Segundo os autores supracitados, entre 1948 e 1954 houve seis presidentes. E, entre 1870 e 1998 , dos 45 presidentes, vinte e três governaram menos de dois anos (1998, p. 36).

(4) Também no Brasil esse termo é utilizado, especialmente pelos militares para referir-se ao que na verdade foi um golpe de Estado.

(5) Os partidos paraguaios são uns dos mais antigos do Cone Sul, superados apenas por aqueles da Colômbia e do Uruguai. Os mais tradicionais, que têm se revezado no poder, são: o Partido Colorado ou Associação Nacional Republicana (ANR) e o Partido Liberal, ambos fundados em 1887. A partir dos anos de 1950, iniciou-se um predomínio do Partido Colorado. O governo de Stroessner promoveu uma fusão entre o Partido, o Estado e as Forças Armadas. Novas mudanças ocorreram somente após 1989 (ABENTE, 1996, p. 39). 
manipulações eleitorais — quanto nos aspectos mais auspiciosos — como o grau de participação da população(6) — o que para esse pensador traz a discussão sobre a importância de se valorizar o ambiente semicompetitivo, no qual há a possibilidade da experiência político-eleitoral como indicativo de avanços, sobretudo no caso guarani. Esses avanços referem-se à questão do desenvolvimento das identidades partidárias, formação dos partidos (os tradicionais), entre outros aspectos. Todavia, o dado mais relevante na história paraguaia é a centralidade dos partidos tradicionais na seara política. Entre 1887 e 1936, todos os governos foram partidários, além do fato de que os dois partidos seguem existindo. Há um interregno em termos de governos estritamente partidários entre o final da década de 1930 e os anos de 1989, quando Stroessner é deposto ${ }^{(7)}$.

Já a relevância da década de 1940 está nas mudanças ocorridas, naquele momento, como o aumento da importância e da influência dos militares na vida política do país e o fato de que desde 1870 houve somente duas ditaduras militares: a de Higino Morínigo (1940-1946) e de Alfredo Stroessner (1954-1989), as quais deixaram marcas profundas na história do país. Outra característica marcante - e recorrente - na política paraguaia é o sistema patrimonialista, que vem de longa data e se mantém incólume em sua história contemporânea. Como corolário tem-se a corrupção que se constitui num dos componentes centrais do sistema político paraguaio sob o governo Stroessner, resultante do aspecto excludente dessa sociedade, em que o grupo de poder no momento resolve assenhorearse do aparato de Estado, na clássica e consagrada não separação entre o público e o $\operatorname{privado}^{(8)}$.

Entretanto, após a construção de Itaipu, surge uma nova elite, enriquecida nesse processo. Com ela emerge um novo ator propriamente dito, o “operador", que substitui o velho caudilho. Agora a conveniência substitui a convicção. Considera-se inclusive uma história política “antes” e "depois” de Itaipu(9).

Faz parte também da cultura política paraguaia a ideia de que o poder se exerce pelo que se convencionou chamar de "política de círculo": pequeno grupo de amigos pessoais sob a ética da confiança e da lealdade, uma forma excludente de exercício do poder (FRUTOS; VERA, 1998, p. 21), desenhando-se, portanto, uma oligarquia, basicamente rural, como forma de organização política, que se reveza no poder. Assim, temos que, de 1887 a 1904, o governo esteve nas mãos do Partido Colorado e de 1904 a 1940 nas do Partido Liberal, com o retorno do Partido Colorado a partir de 1954 com Alfredo Stroessner, até sua derrocada em 1989. A passagem do poder de um para outro

(6) O autor assevera que, entre 1910 e 1930, houve mudanças significativas na legislação eleitoral, avançando-se para eleições livres, culminando com eleições competitivas em 1928, com a participação de cerca de $11 \%$ da população. Que é um bom número para aquele período e circunstâncias (1996, p. 40).

(7) Stroessner integrava o Partido Colorado, no entanto, era não um militante — ou um homem de partido — propriamente dito, mas antes teve uma relação mais formal com este que foi um instrumento útil a seus objetivos de domínio.

(8) Cf. Carlos Martini e Miriam Yore 1998. Esses autores partem do princípio de que a corrupção foi um dos componentes do sistema de governo no país e também uma das formas encontradas de legitimação, que se mantém nos governos pós-Stroessner.

(9) Conforme diversos autores especialistas em política paraguaia. CF. Carlos Martini (1998), Rigoberto Zarza (1998), Diego Abente (1989), Fernando Masi; Dionísio Borda (2002), entre outros. 
nunca foi de forma pacífica, isto é, mediante acordos ou negociações. O que de fato sempre houve foi o predomínio de uma cultura da violência, como uma das características da cultura política paraguaia.

Desta maneira, podemos encerrar essa breve descrição da tradição política paraguaia que antecede ao período Stroessner, a qual na verdade não será alterada em sua essência ao longo de sua estada no poder. De qualquer modo, nos serve como fio condutor e modo de apresentar suas principais características e, ao mesmo tempo, indicar as dificuldades e as vicissitudes pelas quais o país tem passado, no que se refere a um dos aspectos fundamentais de sua existência enquanto Estado independente, isto é, o acesso ao poder e a sua organização política. Neste sentido, as afirmações que já se fizeram e as que se seguem — em referência à sua fragilidade institucional — têm um lastro na sua história e não apenas como uma visão caricata ou mesmo meramente negativa que se faz do país.

Por esta razão, o período de transição democrática representará mudança nessa perspectiva, todavia, essa transição vai se iniciar, paradoxalmente, com um golpe militar em 3 de fevereiro de 1989. Entretanto, não se pode negar que, embora de forma anômala, foi por essa via que se iniciou um novo ciclo na história paraguaia ${ }^{(10)}$.

\section{Política e PODER no Regime Stronista}

Muito se tem falado a respeito do período, da era, da herança desse regime. Isto ocorre por inúmeras razões. Convém enumerá-las e depois trabalhá-las pormenorizadamente. Trata-se de um período sintomático para a vida política, econômica e social paraguaia. Representou uma faceta de sua história, na qual somente um presidente governou cerca de 34 anos, com oito reeleições, quiçá, caso único no continente, com inúmeras particularidades, constituindo-se por si só um modelo político, o stronismo ${ }^{(11)}$.

O stronismo não será analisado e discutido em sua totalidade, mas será apenas tomado como referência e sinônimo de grandes transformações, bem como de sua gravidade para a democracia paraguaia, mais os resultados e as consequências daí advindas, tais como: os da exclusão social, do enriquecimento ilícito de uma minoria, da corrupção e impunidade, da pobreza e do exercício autoritário do poder, para ficarmos nos aspectos mais óbvios e triviais daquela realidade.

(10) Na verdade, pode-se classificar a queda do governo Stroessner como resultado de um golpe palaciano. Ou, nas palavras de José Luis Simon G., "es un ejemplo típico de una transición iniciada desde arriba y provocada por la crisis de descomposición interna de una tirania tradicional” (1992, p. 43). O também general Andrés Rodriguez era membro do Partido Colorado e o segundo homem forte na hierarquia do poder, além de possuir um certo grau de parentesco com seu antigo comandante.

(1 1) Como já declarado na Introdução deste artigo, adotaremos aqui a expressão espanhola Stronismo frequentemente utilizada por boa parte dos analistas paraguaios para caracterizar o regime instaurado por Alfredo Stroessner, a partir de 1954. Por vezes, encontramos também a expressão Stronato. Esse termo é assumido em razão de se considerar o governo Stroessner como um modelo político em função de suas particularidades as quais serão melhor discutidas ao longo deste trabalho, quando da apresentação dos modelos interpretativos propostos por vários estudiosos desse período. Portanto, também por uma questão de preferência abdica-se da expressão Stroessnerismo em língua portuguesa. 
Na década de 1970, auge e consolidação do governo Stroessner, houve um forte crescimento econômico (cf. tabela abaixo), bem como a modernização de sua economia e, ainda, a guinada de sua política externa na relação com as duas potências locais (Brasil e Argentina), mas, neste caso inclinando-se definitivamente para o Brasil.

\section{Tabela 1 - Evolução do crescimento econômico paraguaio}

\begin{tabular}{|l|c|l|l|}
\hline \multicolumn{1}{|c|}{ Período } & $\begin{array}{c}\text { Taxa de } \\
\text { crescimento }\end{array}$ & \multicolumn{1}{|c|}{ Evento econômico } & \multicolumn{1}{|c|}{ Evento político } \\
\hline $\mathbf{1 9 6 5 - 1 9 7 3}$ & $4,2 \%$ & Binacional Itaipu & Consolidação autoritária \\
\hline $\mathbf{1 9 7 4 - 1 9 8 1}$ & $9,0 \%$ & Boom da soja e do algodão & Consolidação autoritária \\
\hline $\mathbf{1 9 8 1 - 1 9 8 8}$ & $2,0 \%$ & Retração & Colapso autoritário \\
\hline $\mathbf{1 9 8 9 - 1 9 9 9}$ & $2,5 \%$ & Estancamento & Transição \\
\hline
\end{tabular}

Fonte: elaborada pelo autor a partir do trabalho de Borda; Masi — 2002.

A entrada em cena do general Alfredo Stroessner em 1954 (via golpe de Estado)(12) significou inicialmente a consolidação da presença militar na vida política do país, iniciada com o fim da Guerra do Chaco (1932-35), sob o comando e governo do coronel Rafael Franco. Até então, os militares constituíam-se no braço armado do poder civil, sem atuação política stricto sensu. Ressalvando-se porém que "Las 'revoluciones' y golpes de estado, aunque ejecutadas por los militares tuvieron casi siempre el aliento de sectores civiles”, por meio de uma representação e atuação partidária, como já referido anteriormente (FRUTOS; VERA, 1998, p. 25).

Stroessner fez um rígido controle do governo e partido - no caso, o Partido Colorado, que em princípio, pelo menos na expressão de seus dirigentes, se opunha à candidatura do general, contudo sucumbiu à imposição dos quartéis — nomeando militares para os ministérios-chave, como os da Defesa, Obras Públicas e Indústria e Comércio (FRUTOS; VERA, 1998, p. 35)(13), dessa maneira estruturando e organizando seu staff político, dando uma conformação personalista a seu governo.

Stroessner iniciou seu governo sob a Constituição de 1940, seguindo com a Constituição de 1967, que foi modificada em 1972, com isso abrindo caminho para sucessivas reeleições, de acordo e segundo suas conveniências ${ }^{(14)}$. Pode-se dizer que se utilizou da

(12) A respeito do surgimento de Alfredo Stroessner, pode-se dizer o seguinte: trata-se de um filho de imigrante alemão, nascido em 1912, ingressando no Exército paraguaio aos 16 anos. Ao lado de Franco e Estigarríbia foi considerado um dos heróis da Guerra do Chaco, onde ganhou reputação por bravura, capacidade de comando e logo demonstrando um senso político apurado (HANRATTY, MEDITZ, 1988). Do ponto de vista político, assumiu o poder mais precisamente em 15 de agosto de 1954, sucedendo a Federico Chaves. Contudo, havia aplicado o golpe em 4 de maio. Entre um e outro, houve um breve período (três dias) em que o país ficou sem governo, em virtude deste último ter solicitado proteção no Colégio Militar. Porém, o resultado foi sua detenção. Enquanto se preparava a "eleição" de Stroessner, assumiu provisoriamente Tomás Romero Pereira, que governou por oito dias, constituindo um gabinete com dois generais e um coronel (FRUTOS; VERA, 1998, p. 34).

(13) Segundo os analistas citados, o Partido Colorado aos poucos foi dominado pelos militares, e seus líderes dissidentes foram exilados por longo período (1998, p. 36).

(14) Conforme Júlio César Frutos e Helio Vera (1998, p. 32), a Carta de 1940 continha normas que permitiam a um presidente governar sem obstáculos. Autorizava o Executivo a ditar decretos com força de lei, eliminava a interpelação 
famosa estratégia da "cenoura e do porrete", ou seja, por um lado, buscou legitimar seu poder interno, aliando-se a setores que tinham algo a ganhar, barganhando com o poder, combinando forte repressão a possíveis opositores e, por outro, soube aproveitar-se de uma conjuntura internacional marcadamente anticomunista. Para tanto, aliou-se de forma incondicional aos EUA, já no contexto da Guerra Fria.

\section{QUAIS SERIAM ENTÃO AS PRINCIPAIS CARACTERÍSTICAS DO REGIME IMPLANTADO POR STROESSNER?}

Deve-se considerar três aspectos essenciais: 1) sua política interna, ou seja, seu modo de governar, a estruturação de seu poder, as forças que compuseram com ele; 2 ) a economia, isto é, a expansão agrícola, sobretudo rumando para leste ${ }^{(15)}$; e 3) sua política externa vinculada às questões internas mais às de natureza geoestratégica.

Neste particular, temos que destacar a construção das binacionais de Itaipu (fundamental) e Yacyretá, sendo que, com a primeira, muda-se o eixo de sua tradicional relação com a Argentina e o Brasil. Acresce-se a isso o fato ou o saldo do desenvolvimento do setor hidrelétrico do país, além de tratar-se de um processo com implicações que vão muito além das demandas econômicas.

Na política interna, Stroessner seguiu a tradição política paraguaia, já mencionada, que é a da cultura da violência. Tanto sua chegada ao poder quanto o seu exercício e consolidação se deram na forma da repressão, da exclusão e da centralização ou concentração do poder em suas mãos. Para melhor entendimento, basta dizer que o governo civil de Federico Chaves (1949-1954), destituído por Stroessner, foi justamente acusado de prática antidemocrática em função das promessas não cumpridas de restauração da ordem demo-crática, pacificação do país, que vinha de uma guerra civil, em 1947, de convocar uma constituinte, entre outros. É também desse período a exigência de filiação ao Partido Colorado como forma de se obter emprego no setor público, bem como iniciar-se na carreira militar (RIQUELME, 1992, p. 31). Dessa maneira, muito do que se seguiu em seu governo em termos de prática política já se fazia presente. Assim segundo Riquelme (1992, p. 31-32):

Este a diferencia de sus colegas del Cono Sur y del Brasil, no tuvo que desmantelar instituciones y/o práticas democráticas. Por el contrario, desde que Stroessner accedió al poder tuvo a su disposición: una constitución autoritária, un sistema político excluyente con partido hegemônico (el Partido Colorado).

Portanto, quando Stroessner chegou ao poder foi saudado tanto interna quanto externamente, pois acreditava-se na possibilidade de democratização do país.

\footnotetext{
a ministros e, ainda, facultava ao presidente dissolver o Legislativo, além de poder decretar Estado de Sítio, bastando "informar" o Congresso, dentre outras características, que certamente convinham a Stroessner.

(15) Também conhecida como a "Marcha del Este" de camponeses sob os auspícios de programas oficiais de colonização dos Departamentos de Caaguazú e Alto Paraná. Houve também um outro tipo de "marcha": o de madeiras para o Brasil, bem como a abertura da economia do país para o contrabando de exportação e importação. Tem-se aí os primórdios de uma economia subterrânea (BORDA, 1993, p. 51).
} 
Pode-se dizer que o poder nessa fase assenta-se na tríade Forças Armadas, Caudilho e Partido. O general Alfredo Stroessner, dadas certas características, costuma ser mencionado como um típico caudilho, isto é, dentre outras particularidades, por ser "aquel sujeto que posee ciertas cualidades personales que explican su autoridad carismática y autoritária” (RAMA apud GALEANO, 2009, p. 61). Bobbio (2007, p. 156), em comum com a definição acima, nos informa que

Esse poder carismático, exercido ao mesmo tempo de forma autoritária e paternalista, e retribuído com a adesão incondicional dos seus homens (e respectivas mulheres), não possuía uma linha política definida e carecia, como se diria hoje, de conteúdo ideológico.

Bobbio destaca também que o termo “caudilhismo”, de origem espanhola, aplica-se a um tipo de regime encontrado na maioria dos países da América espanhola que, em boa medida, corresponde à atuação e à forma de ser de Alfredo Stroessner ${ }^{(16)}$.

Em seu governo, teve grande importância a consecução de uma aliança cívico-militar na qual fez-se notar a forte presença dos militares tanto na esfera estatal quanto na vida empresarial. Acentuaram-se, também no período, a corrupção e a usurpação do poder por parte de uma burocracia instalada nos postos-chave da administração que manipulava licitações, detinha controle das terras públicas, definia preços, além de proceder à evasão dos impostos, enfim obtendo um completo domínio do Estado, combinado com repressão a qualquer tipo de denúncia das irregularidades (BORDA, 1993, p. 60) ${ }^{(17)}$.

O Estado, segundo Carlos Martini e Myriam Yope (1998, p. 112), naquele período - e poderíamos incluir até os dias atuais — tinha um papel de grande "empleador y distribuidor de oportunidades de negócios para un vasto tejido de caudillos”. Neste sentido, basta uma olhada no sucessivo crescimento do número de funcionários públicos, como mencionado nos diversos meios de comunicação por ocasião da posse de Fernando Lugo $^{(18)}$. Além desse fato, havia a questão do vínculo entre o Partido Colorado e o funcionalismo como garantia de empregabilidade, incluindo-se a filiação de militares ${ }^{(19)}$. Ou seja, pertencer a seus quadros sempre foi um pré-requisito para tal fim ${ }^{(20)}$. Isso refletiu-se muito fortemente logo nas primeiras eleições no período de transição, com a vitória inconteste do Partido. Consequentemente, a ideia de uma possível oposição deve ser entendida no âmbito das dissidências no interior do próprio partido e não exatamente

(16) Deve-se levar em conta, porém, que essa definição não é bem aceita entre os analistas paraguaios, ou pelo menos não é consenso, como será visto mais adiante nos modelos interpretativos desse regime.

(17) Denúncias, sobretudo oriundas dos estudantes, camponeses e agentes pastorais progressistas dentre outros (BORDA, 1993, p. 60).

(18) Atualmente, esse inchaço constitui-se em um grande problema, pois a máquina estatal, entre 1989 e 2007 , aumentou consideravelmente o número de funcionários, saltando de 80 mil para 240 mil, o que representa $4 \%$ do total da população. Cf. O Estado de S. Paulo, 21.4.2008. A respeito desse assunto, há um extenso debate sobre a necessidade da reforma do Estado paraguaio. Conferir: Borda, Masi (2002), Simon G. (1989), entre outros.

(19) Consta que nos Requisitos necesarios para el ingreso al colegio militar "Mcal. Francisco Solano Lopez", havia um item em DATOS SOBRE LA MADRE/PADRE destinado a informar a SECC. COLORADA A QUE PERTENECE e FECHA Y LUGAR DE AFILIACIÓN. Citado por Marcial Antonio Riquelme (1992).

(20) Este componente e característica da vida política paraguaia (Partido, Estado) perpassa todos os estratos sociais (MARTINI; YOPE, 1998, p. 113). 
no surgimento de outra força política capaz de se constituir em alternativa de poder no período.

Há uma discussão que se deve levar em conta a respeito do que se chama de stronismo, enquanto um modelo político ocorrido na história recente paraguaia. Esse debate insere-se num contexto mais amplo, a respeito das características do autoritarismo político na América Latina. Trata-se de um tema explorado por diversos pensadores latino-americanos, dentre os quais Fernando Henrique Cardoso, Fernando Masi, Roberto Cespedes, Marcial Antonio Riquelme e Guillermo O’Donnell. Um dos resultados acerca dessa questão é o clássico - Transições do regime autoritário: América Latina ${ }^{(21)}$ — que trata, de forma comparativa, os autoritarismos do sul da Europa e da América Latina. Essas discussões ocorrem basicamente a partir de duas raízes: materialistas e weberianas ${ }^{(22)}$. Assim o que nos importa é que, entre as conclusões aceitas, verificaram-se dois tipos básicos de autoritarismo existentes nesses pagos latinos, levando-se em conta os Estados e seus respectivos regimes: o autoritarismo burocrático (regimes militares modernos) e outro mais tradicional, no qual se situa o Paraguai. Não se pode esquecer ainda de que a América Latina é constituída por inúmeros países, com realidades muito díspares, o que obviamente traduz-se em respostas e tradições políticas muito heterogêneas em que pese as possíveis similaridades em aspectos mais amplos, como o fato de serem países periféricos e marginais no cenário internacional, mais os déficits democrático, econômico e social que lhes são característicos.

Por isso, segundo Fernando Masi, há que se considerar as conjunturas político-econômicas, os diferentes tipos de alianças político-sociais, etc. De qualquer modo, trata-se de experiências políticas já consumadas — em geral, de regimes militares —, postas para discussão e entendimento. Além disso, há o dado de que, em alguns casos, países como o Brasil possuírem um alto padrão de modernização econômica.

Contudo, ainda conforme Masi, citando Alain Rouquié, é importante frisar que os regimes militares na América Latina não engendraram nem tampouco esboçaram o surgimento de um novo modelo de Estado. Além disso, não havia uma clara ideologia que promovesse coesão e legitimação de poder. Na América Latina, não se verificou um sentido revolucionário como na Europa dos regimes autoritários fascista e nazista (dos anos de 1920 e 1945, que se contrapunham à democracia liberal) com o intuito de uma "nova ordem”, mas antes um sentido exclusivamente reformista. E isso na América Latina tem validade tanto para "un régimen militar sofisticado como el brasileño, como para 'un militarismo arcaico como el Paraguay de Stroessner”. E ainda por acréscimo, consoante Atílio Borón (apud MASI, p. 24), seria mais apropriado, na maioria dos casos referir-se a uma militarização do Estado.

(21) Esses estudos foram publicados em quatro volumes, sendo Guillermo O’Donnell, um dos organizadores. Cf. referências bibliográficas.

(22) Essa discussão é apresentada por Fernando Masi (1989), mostrando a perspectiva de Fernando Henrique Cardoso na qual busca caracterizar os regimes autoritários na América Latina, porém, fazendo reparos nos conceitos de Regime e Estado. 
De acordo com Marcial Antonio Riquelme (1992, p. 25), com relação ao Paraguai, diferentemente dos demais países da América Latina, há uma escassa literatura que aborda os trinta e cinco anos do governo Stroessner. Para esse autor, isso se deve talvez à dificuldade em caracterizar esse regime segundo as fórmulas clássicas como a marxista ou a funcionalista, assim "optaran por esquivar el tema o referirse al mismo dándole un tratamiento marginal”. Isso se nota, por exemplo, no trabalho de Samuel Huntington a respeito das ondas democráticas pelas quais passaram boa parte dos países latino-americanos, em que o Paraguai é apenas citado em raros momentos sem, no entanto, receber qualquer tratamento específico.

No mais houve um primeiro trabalho em língua inglesa do norte-americano Paul Lewis (1980) que caracteriza esse regime como sendo de uma ditadura personalista tendo à frente um caudilho modernizador, como produto de uma cultura autoritária típica de sua história. Nas ciências sociais latino-americanas, as influências maiores são os trabalhos do argentino Guillermo O’Donnell e do brasileiro Fernando Henrique Cardoso, que se referem de forma muito superficial ao regime de Stroessner, qualificando-o como "autoritarismo tradicional" e uma "reedição do militarismo caudilhista respectivamente (RIQUELME, 1992, p. 27).

No Paraguai, propriamente dito, a partir da década de 1980, começou-se a produzir reflexões mais sistematizadas a respeito da caracterização do regime do general Alfredo Stroessner em função do retorno de inúmeros cientistas sociais ao país após exílios a que foram submetidos.

Pode-se dizer que existem três tipos clássicos de regimes políticos: totalitarismo, autoritarismo e democracia — de acordo com Huntington por exemplo. Neste caso o regime perpetrado por Stroessner e em razão de suas características possui alguns traços comuns aos dois primeiros conforme quadros abaixo:

\section{Quadro 1 - Características dos regimes: totalitário e stronista}

\begin{tabular}{|l|l|}
\hline \multicolumn{1}{|c|}{ *Totalitarismo } & \multicolumn{1}{|c|}{ Stronismo } \\
\hline $\begin{array}{l}\text { Uma ideologia elaborada; todos devem aderir; } \\
\text { contém um projeto de uma nova sociedade. }\end{array}$ & Sem ideologia. \\
\hline Um partido único, dirigido por um ditador. & $\begin{array}{l}\text { Identificação do Partido Colorado com o } \\
\text { Estado; partidarização das Forças Armadas - o } \\
\text { sistema não era de partido unico, era apenas } \\
\text { hegemônico. }\end{array}$ \\
\hline $\begin{array}{l}\text { Sistema de terror físico/psicológico, } \\
\text { implementado via partido/polícia secreta. }\end{array}$ & $\begin{array}{l}\text { Organismos de segurança e métodos de terror a } \\
\text { cargo do próprio Partido Colorado. }\end{array}$ \\
\hline Controle dos meios de comunicação de massa. & Controle dos meios de comunicação. \\
\hline Sistema econômico de planificação central. & $\begin{array}{l}\text { Sem planificação central - mas ao sabor dos } \\
\text { interesses específicos do regime. }\end{array}$ \\
\hline
\end{tabular}

Fonte: elaborado pelo autor — * Friedrich e Brzezinski — 1965 (citado por RIQUELME, 1992, p. 32). 
A partir do quadro acima, pode-se dizer que, embora haja pontos em comum e semelhanças entre totalitarismo e stronismo, isso não nos permite caracterizar este enquanto um sistema real e puramente totalitário, em razão da ausência de uma ideologia, tampouco a vigência de um sistema de partido único, bem como sua formulação econômica. O mesmo não se pode dizer quando se compara o stronismo com o autoritarismo, de acordo com o Quadro 2, pois o regime de Stroessner possui muitos aspectos em comum com as características mais gerais dos regimes autoritários.

Contudo, como assevera Riquelme (1992, p. 36-37), isso se modifica quando tomamos como base a proposição de O’Donnell, qual seja, a do "burocrático autoritário": existem algumas diferenças básicas, conforme o Quadro 4, as quais se relacionam entre outras às questões da forma de exercício do poder, a situação das Forças Armadas, a função dos partidos e à legitimidade do regime.

\section{Quadro 2 - Características dos regimes: autoritário e stronista}

\begin{tabular}{|l|l|}
\hline \multicolumn{1}{|c|}{ *Autoritarismo } & \multicolumn{1}{c|}{ Stronismo } \\
\hline Sistemas políticos com pluralismo limitado. & Espaço político outorgado e restringido. \\
\hline Sem ideologia elaborada e diretriz. & Falta de uma ideologia coerente - há algumas \\
mentalidades: coragem, heroísmo da raça \\
paraguaia.
\end{tabular}

Fonte: elaborado pelo autor — * Linz — 1975 (citado por RIQUELME, 1992, p. 33).

\section{Quadro 3 - Diferenças entre o regime stronista e os burocráticos-autoritários}

\begin{tabular}{|l|l|}
\hline \multicolumn{1}{|c|}{ Regime stronista } & \multicolumn{1}{c|}{ Burocrático autoritário } \\
\hline Caráter personalista de poder. & Estamento militar. \\
\hline Orientação partidária das Forças Armadas. & Sem identificação partidária. \\
\hline Apoio de um partido político ao regime. & $\begin{array}{l}\text { Exceto o Brasil, não há partidos preexistentes } \\
\text { nem a criação a partir do governo. }\end{array}$ \\
\hline $\begin{array}{l}\text { Orientação legalista do regime - busca de de } \\
\text { uma fachada de legitimidade. }\end{array}$ & É claro o caráter de regime de exceção. \\
\hline
\end{tabular}

Fonte: elaborado pelo autor.

Realizadas essas discussões mais gerais nas quais se mostraram as semelhanças e dessemelhanças do regime do Stroessner com as fórmulas clássicas de regimes políticos, podemos, na sequência, de forma sintética, apresentar as caracterizações do governo do 
general Stroessner, propostas por quatro autores paraguaios que, nesse debate mais amplo como acima referido, estabeleceram alguns modelos de interpretação, buscando as especificidades e as sutilezas do regime.

De início, podemos dizer que há uma certa concordância - por parte dos analistas paraguaios — na existência do que se poderia chamar de uma tríade de poder, ou seja: Partido, Forças Armadas, Governante. Assim teríamos um primeiro modelo proposto por Roberto Cespedes (1982) que seria o da Ditadura Militar, o Estado Prebendário, conforme Esteban Caballero (1985), o do Estado Onívoro, na visão de Benjamín Arditi (1987) e, por último, divergindo dos anteriores, teríamos um modelo de base weberiana, na concepção de Marcial Antonio Riquelme (1992) que é o do Neossultanismo. Esquematicamente, então, teríamos:

\section{Modelo 1 - Ditadura militar}

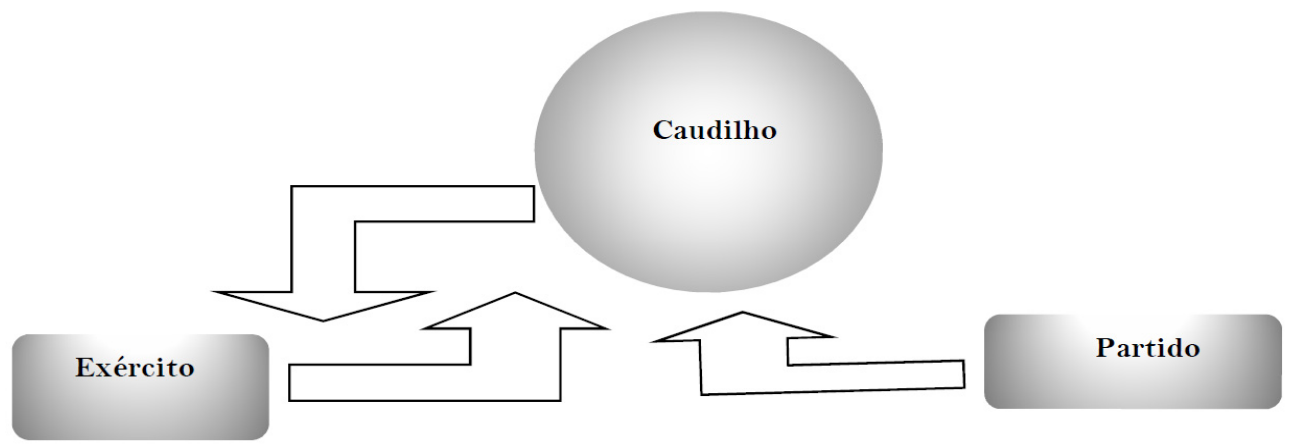

Fonte: esquema elaborado pelo autor.

Nesse modelo explicativo, Cespedes considera que se pode encontrar no regime stronista a combinação de três elementos clássicos de regimes autoritários: ditadura militar, fascismo e bonapartismo.

Trata-se, no caso do primeiro elemento, de uma ditadura com caudilho, na qual o Exército tem um poder de fato com fortes vínculos com o caudilho que, por sua vez, é oriundo de suas hostes. Aqui o Exército detém o monopólio da violência, garantindo assim o domínio sobre os demais setores da sociedade, incluindo o partido, no caso o Colorado.

O partido por sua vez representa o lado fascista do Estado, já que se trata de um partido de base rural com domínio sobre o campesinato, naquela altura, o maior segmento da sociedade. Por ser um partido de governo, desmobiliza a classe camponesa utilizando-se de práticas totalitárias.

O elemento bonapartista dá-se em função de uma conjuntura que lhe é adversa e na necessidade da busca do equilíbrio com vistas a sua legitimação, em que operam a figura de líderes carismáticos/predestinados que controlariam a classe campesina com 
desenvolvimento de aparatos repressivos. Poder-se-ia entender aqui a existência de uma estrutura oligárquica típica de países de bases rurais muito arraigados, herdados ainda do período colonial, las haciendas.

Nesta tríade de poder - conforme o esquema acima - há uma relação de mútua influência entre Exército e caudilho, e a proeminência de ambos sobre o Partido. Há também um elemento muito importante a ser considerado, qual seja, a utilização de métodos prebendários como condição de manutenção da coesão entre Partido e Exército.

\section{Modelo 2 - Estado Prebendário}

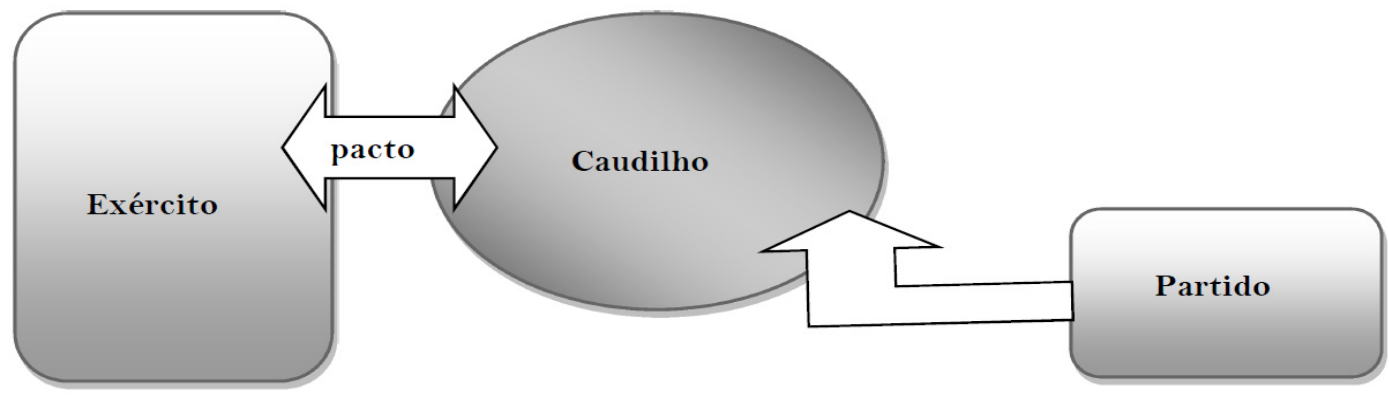

Fonte: esquema elaborado pelo autor.

No Estado prebendário, temos uma coincidência com o modelo anterior, já que leva em conta a tríade de poder, porém, concebendo esse regime como uma Ditadura Militar com Partido. Atribui um peso maior ao Exército, todavia, este se submete ao caudilho mediante um pacto que se dá pelo sistema de prebenda, enquanto fator de coesão. A partir dessa esfera, o "sistema" irradia-se pelos demais setores da sociedade. Conforme Esteban Caballero (apud MASI, 1989, p. 33), um sistema de prebendas e privilégios pode ser entendido como

un conjunto de prácticas fincado sobre la repartición de puestos públicos, oportunidades de vida y de sustentación económica, de bienes y servicios y de derechos excepcionales. Su finalidad es la de cooptar adherentes al proyecto del bloque en el poder mediante un intrincado mecanismo de intercambios en donde el individuo o los grupos sociales le dan su apoyo al régimen, a cambio de un lugar en la repartición.

Aqui há uma particularidade a respeito do Exército. As Forças Armadas continuam no poder — uma constatação —, contudo, os oficiais negociam com o caudilho sua obediência e lealdade, não colocando em xeque seu poder, mediante prebendas e privilégios. Assim o ditador não concentra todo o poder em suas mãos, aos oficiais cabem cotas de poder militar, econômicos e políticos. Por esse modelo explicativo, o poder não está concentrado exclusivamente na mão do caudilho, muito embora, de certo modo, tenha a prerrogativa das iniciativas. 
No que se refere ao Partido Colorado, há uma diferença na forma de sua cooptação com relação ao que ocorre com o Exército. A este lhe compete a legitimação do regime perante a sociedade. Entretanto, o custo é a perda de sua autonomia relativa, tornando-se, na verdade, um instrumento do caudilho, pois sua função não menos importante (é bom ressaltar) será a de fazer chegar aos estratos inferiores o sistema prebendário, criando uma rede de redistribuição das prebendas. Para isso, utiliza-se de um semnúmero de mecanismos de cooptação: empregos na administração pública, distribuição de terras, licitações e outros privilégios.

Também compete ao partido a formação de quadros políticos, vigilância e repressão contra a população de modo geral, de acordo com as necessidades. Nessa perspectiva tanto quanto do modelo 1 - o partido ocupa uma posição subalterna na tríade de poder, porém com uma função nada desprezível, dando-lhe certa margem de manobra.

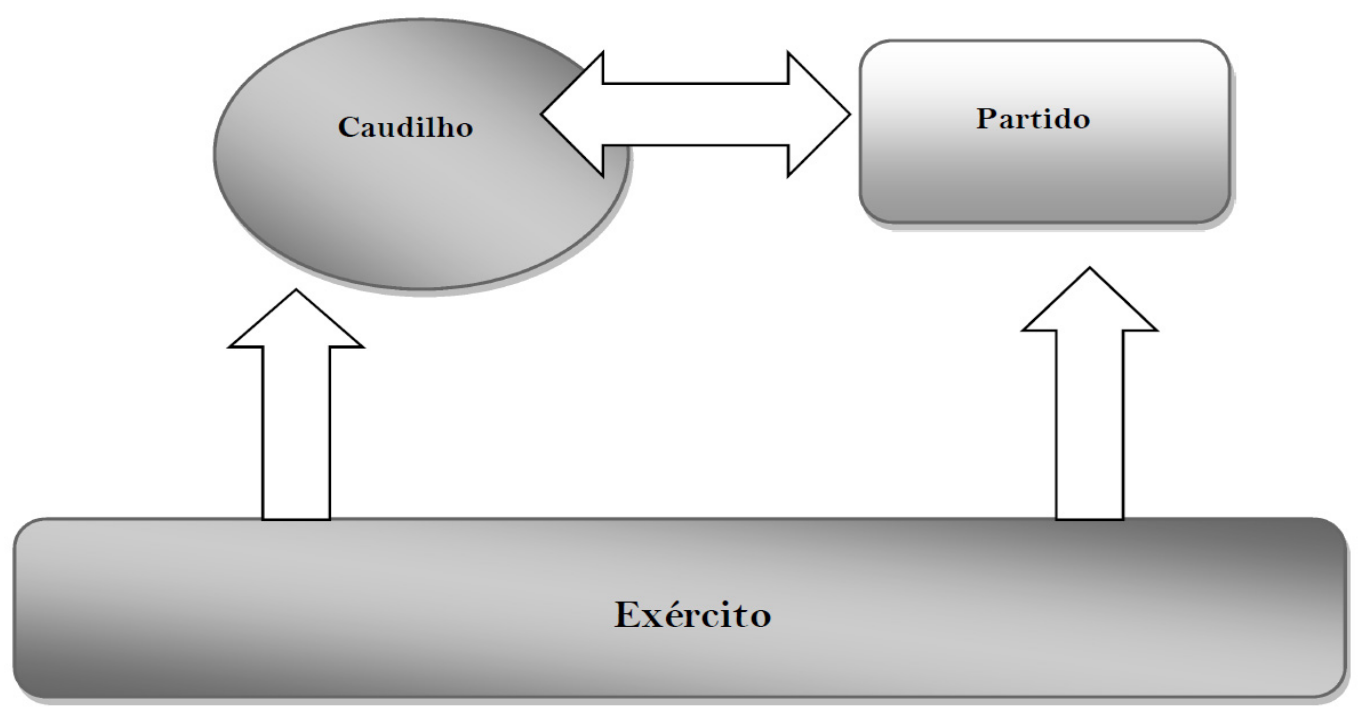

Fonte: Esquema elaborado pelo autor.

A terceira forma de explicação para o regime é a do Estado Onívoro, segundo a qual haveria por parte do Estado, na figura do caudilho, uma vontade de "devorar" toda e qualquer diferença, ou mesmo alguma forma social que não se submeta a esse poder, cuja estrutura é aquela da hierarquia na relação Estado-sociedade civil, na qual o esquema de decisão estaria na base do comando-obediência, amigo-inimigo. Além disso, com a desativação das organizações populares, o Estado absorve e assume o papel da sociedade civil no que se refere às demandas sociais. Esse processo ou mecanismo, Benjamin Arditi qualificou de corporativismo estatal. O outro mecanismo seria aquele chamado de ritualização da política, no qual vige um pluralismo limitado de partidos, dando ares de democracia. De um lado, há uma redução ao mínimo de expressão dos partidos de oposição e, por outro, há um aumento do poder do partido governante (partido de patronazgo na expressão paraguaia). O Partido opera como um fator de cooptação e, ao mesmo tempo, 
de exclusão. Entre outras características do Partido Colorado, nessa fase temos aquela de ser o executor de uma repressão de tipo policial, por intermédio das milícias coloradas. O partido detém o monopólio dos meios de comunicação, além de ter um papel assistencialista que desempenha nos mais remotos rincões do país. Esse conjunto de tarefas, de certo modo, o descaracteriza como um partido moderno.

O Partido Colorado, sinteticamente falando, é um partido sem nenhuma prática política que se possa chamar de democrática, facilmente verificável desde sua fundação como ficou demonstrado no início deste capítulo. Stroessner, na verdade, não precisou e nem pretendeu fundar um outro partido, mas aproveitou-se de uma estrutura já existente, o que a partir da década de 1960 possibilitou sua expansão por meio das seccionais exis-tentes em todo o país. Soube enfronhar-se em seu interior e se constituir enquanto uma força política interna capaz de impor seu projeto político. As táticas foram as da cooptação, coerção e estímulo às diferenças — rivalidades — internas. Nos partidos de oposição, bem como no próprio partido, utilizou-se largamente do recurso à repressão de forma implacável, quando necessário e oportuno ${ }^{(23)}$.

O Partido, por sua vez, não perdeu totalmente sua autonomia - já que na verdade era parte do governo e internamente sempre houve intensa luta entre os seus representantes tradicionais e os adeptos do stronismo - principalmente nesse processo coube-lhe a função de execução e verificação do cumprimento das obras estatais de infraestrutura e colonização de terras. Com isso, arrebanham-se as massas campesinas, promove-se a filiação massiva dos funcionários públicos, que redunda em uma incorporação desses e daqueles ao projeto político do partido. A partir dessa estrutura, pôde manter-se no poder ainda na década de 1990, como a principal força política, mesmo após a derrocada do regime stronista, muito embora tenha sido a base de sustentação e ao mesmo tempo a face civil desse regime.

Tal sistema de partido passa a ser a única forma de participação cidadã, ou seja, trata-se de um fator limitador e inibidor de qualquer outra forma de participação que não aquela, de certa maneira, prevista, aceita e tolerada, como se o Estado por si só provesse todas as necessidades políticas e econômicas da sociedade.

Em suma, com Stroessner institui-se um tipo de autoritarismo - burocrático por um lado, isto é, aqueles de regimes militares modernos, mas tradicionais, cujas bases estão assentadas no exercício do poder pela tríade Exército, Partido, governante ou caudilho, sendo este último o articulador e mentor político. Trata-se de um modelo patrimonialista, permeado por um sistema de prebendas que dá sustentação e coesão ao grupo no poder, de tal sorte que uma das funções do Partido Colorado foi justamente a da distribuição dessas prebendas e, ao mesmo tempo, a desmobilização da sociedade civil. Os principais beneficiários desse sistema foram os da cúpula militar e o próprio

(23) Segundo a Latin American Studies Association (LASA), não se tem dados precisos a respeito das mortes por torturas ou simples assassinatos, mas estima-se que a maior parte deu-se entre 1958-1963, período de consolidação do regime. As principais vítimas estavam entre membros dissidentes do Partido Colorado, dos partidos de oposição, dirigentes dos trabalhadores e campesinos (1990, p. 286). Contudo, de acordo com a LASA, estima-se entre 45 e 55 o número de mortos e desaparecidos na última década do regime. Cf. também Paz, González, Aguilar (1994), a respeito dos arquivos da Polícia Política de Stroessner. 
caudilho. E como "ganho", do ponto de vista do regime, houve ainda a vantagem das parcas possibilidades da sociedade civil desenvolver-se ou oferecer qualquer resistência, já que de certo modo parte dela foi aliciada, tornando-se cúmplice e sócia nesse esquema. Consideremos também como logro do regime a quase eliminação da participação política da população e, por consequência, o impedimento do surgimento de uma outra racionalidade, ou seja, aquela da sociedade civil organizada.

Finalmente, temos um quarto modelo, como segue abaixo, intitulado de neossultanismo, no entendimento de Marcial Antonio Riquelme.

\section{Modelo 4 - Neosultanismo}

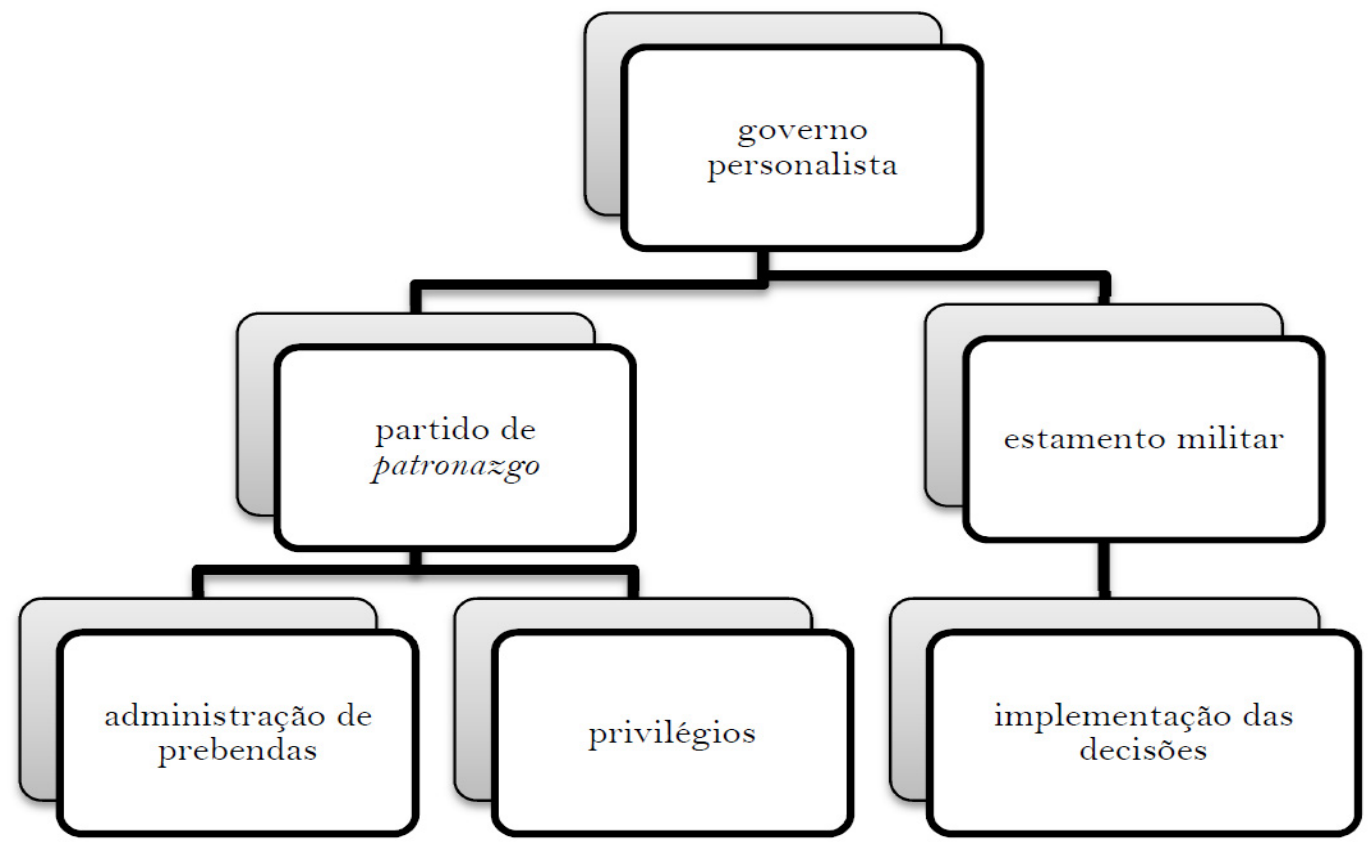

Fonte: esquema elaborado pelo autor.

O modelo sultanista tem como base - como de resto é recorrente nos autores paraguaios - as definições dos tipos de dominação encontradas em Economia e Sociedade, de Max Weber. A partir desse autor, Juan Linz procede a uma reelaboração buscando uma acomodação no seu entender mais adequada ao caso paraguaio ${ }^{(24)}$. E assumida por Marcial Antonio Riquelme (1992, p. 40).

Como podemos observar, no modelo acima, assomam as seguintes características:

1) O poder estava incontestavelmente nas mãos do Chefe de Estado, de forma discricionária, não havendo uma ideologia explícita, nem instituições independentes, mas submetidas ao Executivo, casos do Legislativo e o Judiciário. 
2) As decisões do Chefe de Estado, no que se refere à sua implementação, por um lado, encontravam guarida em determinados setores das Forças Armadas que, segundo Riquelme, caracterizavam-se por ser "un estamento militar sectário, es decir, no institucional” e, por outro, eram executadas e implementadas pelo partido, responsável também pela administração das prebendas e privilégios.

3) Do ponto de vista administrativo, há uma burocracia com certo grau de especialização, contudo, todo o ritual de contratação de funcionários e mesmo seu comportamento profissional estava mais próximo à subserviência com relação ao Chefe de Estado que aos parâmetros modernos da administração pública, os quais envolvem procedimentos racionais e legais.

4) Há também e, por extensão, o aspecto da lealdade ao chefe com base no temor e nas recompensas materiais auferidas como prêmio.

5) Por último, tem-se a postura do Chefe de Estado como uma espécie de “dono” do país. Este é visto como sua propriedade e de seus auxiliares mais imediatos. Isso decorre do exercício do poder de forma personalista e livre de qualquer controle ou valores basilares. Dispor dos bens públicos, utilizar os ativos econômicos, estabelecer monopólios estatais contrários aos interesses coletivos, em benefício próprio, foram a tônica e práticas usuais. Dessa maneira, explica-se, por exemplo, a falta de uma política econômica mais clara e consequente.

Segundo Riquelme (1992, p. 41), citando Juan Linz, o fato de o Paraguai ser um país com as dimensões territoriais de base eminentemente rural, portanto, de economia agrícola, de ter poucos centros urbanos importantes que pudessem ser base para indústrias e comércio, o tornaram presa fácil de regimes de tipo sultanista. Marcial Antonio Riquelme (1992, p. 42), por meio desse modelo explicativo descrito, refuta as qualificações dadas ao tipo de regime do general Alfredo Stroessner, dizendo que este, como já demonstrado, não foi um regime exclusivamente de tipo totalitário, tampouco autoritário burocrático, ou mesmo uma ditadura tradicional capitaneada por um caudilho. $\mathrm{Na}$ verdade, trata-se de uma dominação que teve como base um sistema de recompensas e castigo, um ordenamento jurídico passível de mudanças, segundo as circunstâncias, além do livre-arbítrio do Chefe de Estado com relação às decisões a serem tomadas, o que torna mais adequada a sua caracterização como a do neossultanismo.

As racionalidades de maior visibilidade nesse processo foram as do Estado, do Partido Colorado e das Forças Armadas. Podemos acrescentar ainda que a forma de poder implementado por Stroessner estava adequada a uma sociedade fortemente agrária, com grau de industrialização incipiente e um sistema partidário cujo perfil não é de tipo populista ou mesmo classista, como se poderia dizer da Argentina ou mesmo do Brasil.

Além desses aspectos supracitados, há de se levar em conta que se trata de um período em que há a transformação de um Estado de características pré-capitalistas, isto é, uma produção basicamente agropecuária calcada em grupos estrangeiros que se utilizavam de um sistema laboral de peonagem, latifúndios nativos tradicionais e 
produção do minifúndio camponês, além da ausência de um mercado interno para um Estado que, pelas razões expostas, se chamou de "capitalista prebendário" (MASI, 1989, p. 14). Há de se ressaltar, ainda, a corrupção como componente do sistema político paraguaio, presente na maior parte de sua história tornando-se um dos pilares de sua reprodução sob o governo Stroessner mantendo-se ainda na década de 1990 e posto para averiguar-se nos anos 2000. E como resultado tem-se o colapso das formas de espaço e participação política da sociedade civil, não só pela violência propriamente dita, mas por intermédio de mecanismos mais sutis que vão minando sua organização.

\section{CONSIDERAÇÕES FINAIS}

Como vimos, na tradição política paraguaia, a violência nas suas variadas formas é o que prevalece como modo privilegiado de alternância no poder. Contudo, há a presença permanente de um sistema partidário cujas origens são centenárias. $O$ que de certo modo surpreende, já que se verifica em outros tempos um sistema eleitoral semicompetitivo, colocando-o em sintonia com alguns países mais avançados na região. Porém, esta situação não deixa de ser ambígua e contraditória em função dos inúmeros governos que foram a um só tempo longevos e efêmeros. Essas características dentre outras são, portanto, herdadas pelo governo de Alfredo Stroessner, que em muitos aspectos vai “aprimorá-las” e ou acentuá-las.

Pelo que foi exposto, ficou claro também a dificuldade na definição desse regime que governou o país por 34 anos. Isto significa dizer que, os modelos apresentados procuraram justamente demonstrar os limites das formulações clássicas de interpretação. Assim, os conceitos de ditadura, totalitarismo ou simplesmente autoritarismo podem não ser suficientes para abarcarem as particularidades do regime. Mas antes deve-se considerar que no conjunto cada modelo apresenta uma explicação a ser levada em conta.

Isto significa dizer que esses modelos concordam em praticamente dois pontos ou seja, um que diz respeito à existência de uma tríade no poder, isto é, o caudilho, as Forças Armadas e o Partido Colorado e outro onde todos reconhecem a presença e a importância da prebenda como fator de coesão dessa estrutura. Cada modelo, no entanto, procura demonstrar o papel, bem como a relevância de cada um desses atores na conformação do poder. De qualquer modo, se não há um ditador propriamente dito, ou as Forças Armadas no comando stricto sensu ou ainda o Partido como sendo o centro difusor de poder, é forçoso reconhecer que a Stroessner deve-se lhe imputar a primazia das iniciativas e articulação dos demais integrantes do poder, com habilidade suficiente para a manutenção e consolidação do regime.

Esse particular não pode ser ignorado nas análises de política Paraguaia desse período e seus reflexos posteriores. Convém ressaltar ainda que, a partir da década de 1960, iniciou-se um processo ou um modelo econômico na tentativa de romper com o isolamento internacional do país, que ficou conhecido como Crecimiento Hacia Afuera, com financiamento do FMI para obras de infraestrutura que permitiam ao país especializar-se em alguns produtos com possibilidades competitivas no mercado internacional (MASI, 1989, p. 50). 
O regime iniciado com Stroessner reproduz boa parte das características do que se observa na maioria dos países latino-americanos, ressalvando-se suas peculiaridades, portanto, não é possível referir-se a ele como sendo puramente burocrático tradicional ${ }^{(25)}$.

Para finalizar essas reflexões, poder-se-ia indagar: Onde estariam as raízes desses regimes encontráveis na maior parte dos países da América Latina? Em parte, levando-se em conta mais os aspectos internos, poderíamos concordar com Fernando Masi (1989, p. 36), para quem,

el origen de este tipo de régimen dado por la incapacidad de las clases dirigentes por resolver problemas conyunturales, y la falta de un proyecto de las mismas; un sistema de exclusión y cooptación a través de la acción de un partido tradicional; y la existencia de un caudillo militar respaldado totalmente por el ejército.

\section{REFERÊNCIAS BibLIOGRÁFICAS}

ABENTE, Diego. Límites y posibilidades: perspectivas de democratización en el Paraguay. Revista Paraguaya de Sociologia, Asunción, año 45, n. 131, ene./abr. 2008.

ACEVEDO, Euclides. Paraguay: transición política y consolidación democrática en el cono sur. Latin America. Documentos y Estudios 72, Madrid: Fundación Friedrich Ebert, 1990.

ACHUGAR, Hugo. Imagens da integração. São Paulo: Memorial da América Latina, Coleção MEMO, 1997.

ARDIDTI, Benjamin. La politicidad de la crisis y la cuestión democrática. Estado, economía y sociedad en el Paraguay. Asunción: CLACSO-PNUD, jun. 1986.

BASTOS, Augusto Roa. Política, poder y democracia en el Paraguay. Revista Paraguaya de Sociologia, año 31, n. 89, 1994.

BOBBIO, Norberto. Estado, governo, sociedade: por uma teoria geral da política. Trad. Marco Aurélio Nogueira. Rio de Janeiro: Paz e Terra, 1987.

BOBBIO, Norberto; MATTEUCCI, Nicola; PASQUINO, Gianfranco. Dicionário de política. 13. ed. Brasília: Universidade de Brasília, 2007.

. Ofuturo da democracia. Trad. Marco Aurélio Nogueira. São Paulo: Paz e Terra, 2000.

BORDA, Dionísio (comp.). Memorándum para el gobierno 2008-2013. Asunción: CADEP, 2008.

La estatización de la economía y la privatización del Estado en Paraguay. Estudios Paraguayos

— Rev. de la Univ. Catolica N. S. Asunción, v. XVII, n. 1-2, 1989-1993.

BORDA, Dionisio; MASI, Fernando. Los límites da la transición: economía y el Estado en el Paraguai en los años 90. Cidesp: Nuestra Señora de la Asunción, 1998.

BRUN, Diego Abende (coord.). Paraguay en transición. Venezuela: Nueva Sociedad, 1993.

CABALLERO, Esteban. Documentos de discusión. Dictadura, estado prebendario y crisis política. Asunción: Centro Paraguayo de Estudios Sociopolíticos (CPES), 1985. 
CENTRO de Análises y Difusión de la Economía Paraguaya. Disponível em: <http://www. cadep.org.py> Acesso em: 6.3.2009.

CESPEDES, Roberto. Emergence and consolidation of a military dictatorship in Paraguay. New Jersey, 1982.

FRUTOS, Julio Cesar; VERA, Helio. Elecciones 1998. Tradición y Modernidad. Asunción: Medusa, 1998.

GALEANO, Luis A. De la apertura otorgada a la transición pactada? Revista Paraguaya de Sociología, año 45, n. 131, p. 53-68, ene./abr. 2008.

. La sociedad dislocada. Asunción: CPES, 2002.

HANRATTY, Dannin, M.; MEDITZ, Sandra W. (eds.). Paraguay: a country study. Washington: GPO, 1988.

LEZCANO, Carlos Maria; MARTINI, Carlos. Fuerzas armadas y democracia: a la búsqueda del equilibrio perdido - Paraguay 1989-1993. Asunción: GCS/CDE, 1994.

LEWIS, Paul. Paraguay under Stroessner. Chapell Hill: University of North Carolina, 1980.

MARTINI, Carlos; YOPE, Myriam. La corrupción como mecanismo de reproducción del sistema político paraguayo. Asunción: CIDSEP/UC, 1998

MASI, Fernando. Los vaivenes de la política comercial externa en una economía abierta. Asunción: CADEP, 2006

. Stroessner la extinción de un modelo politico en Paraguay. Asunción: Nanduti Vive/Intercontinental, 1989.

. El contexto internacional en la transición de la democracia. In: BRUN, Diego Abende (coord.). Paraguay en transición. Venezuela: Nueva Sociedad, 1993.

MENEZES, Alfredo da Mota. A herança de Stroessner: Brasil/Paraguai 1955-1980. Campinas: Papirus, 1987.

O’DONNELL, Guillermo. Introdução aos casos latino-americanos. In: O’DONNELL, Guillermo; SCMITTER, Philippe C.; WHITEHEAD, Laurence (orgs.). Transições do regime autoritário: América Latina. São Paulo: Vértice; Revista dos Tribunais, 1988.

O’DONNELL, Guillermo; SCMITTER, Philippe C.; WHITEHEAD, Laurence (orgs.). Transições do regime autoritário: América Latina. São Paulo: Vértice; Revista dos Tribunais, 1988.

PAREDES, Roberto. Entidades y personajes de la transición. Asunción: AGR, 2001.

PAZ, Alfredo Boccia; GONZÁLEZ, Myrian Angélica; AGUILAR, Rosa Palau. Es mi informe. Los Archivos Secretos de la Policía de Stroessner. Asunción: CDE, 1994.

RIQUELME, Marcial Antonio. Stronismo, golpe military apertura tutelada. Asunción: CDE/RP, 1992.

. Discusión de las relaciones fuerzas armadas/sociedad civil en el Paraguay. Propuetas Democráticas, Asunción: Universidad Nacional de Asunción, año I, v. I, n. 3, p. 75-93, jul./ set. 1994.

WEBER, Max. Ciência e sociedade: duas vocações. São Paulo: Cultrix, 2009.

. Economia e sociedade: fundamentos da sociologia compreensiva. Brasília: UnB, 1991. v. 1. 